\title{
Penambahan Tepung Temu Putih (Curcuma zedoaria Rosc.) untuk Mengoptimalkan Profil Saluran dan Organ Pencemaan Ayam Pedaging
}

\section{(Additioning of White Tumeric Powder to Optimize Gastrointestinal Track Profile and Broiler Organs)}

\author{
Anggraini AD, Widodo W, Rahayu ID, Sutanto A \\ Prodi Peternakan Fakultas Pertanian-Peternakan Universitas Muhamadiyah Malang \\ Jl. Raya Tlogomas No.246 Malang, Jawa Timur \\ apriliana@umm.ac.id
}

\begin{abstract}
This study was aimed to determine the effects of white tumeric powder addition in diets on gastrointestinal track and broiler organs profile. The study was conducted for 40 days using 100 broiler. The treatment diets were control basal diet (P1); P1+1\% white tumeric powder addition (P2); $\mathrm{P} 1+2 \%$ white tumeric powder addition (P3); $\mathrm{P} 1+3 \%$ white tumeric powder addition (P4). The data collected were analyzed by completely randomized design in oneway arrangement. Significant differences between treatments were further tested with Least Significance Different. Results of this study showed that the addition of white tumeric powder in the diets affect relative length of jejunum but did not affect length of duodenum, ileum, and absolute weight of organs. It could be concluded that white tumeric powder used until $3 \%$ in diets did not affect gastrointestinal track profile and broiler organs.
\end{abstract}

Key words: Broiler, white tumeric powder, gastrointestinal track, organ profile

\begin{abstract}
ABSTRAK
Penelitian ini bertujuan untuk mengetahui pengaruh penambahan temu putih dalam pakan terhadap profil saluran dan organ pencernaan ayam pedaging. Penelitian dilaksanakan selama 40 hari menggunakan 100 ekor day old chick strain Cobb. Perlakuan yang diberikan berupa: pakan basal (P1); P1+temu putih 1\% (P2); P1+temu putih 2\% (P3); P1+temu putih 3\% (P4). Setiap perlakuan dilakukan pengulangan sebanyak 5 kali. Data yang diperoleh dianalisis variasi Rancangan Acak Lengkap pola searah. Perbedaan antar perlakuan diuji lanjut menggunakan uji Beda Nyata Terkecil. Hasil penelitian menunjukkan bahwa pemberian tepung temu putih memberikan pertambahan nilai panjang relatif jejunum, namun tidak memberikan pengaruh terhadap panjang duodenum, panjang ileum, dan berat organ perncernaan ayam broiler. Kesimpulan dari penelitian yang telah dilakukan bahwa penambahan tepung temu putih hingga 3\% pada pakan tidak memberikan respon terhadap profil saluran dan organ pencernaan ayam pedaging.
\end{abstract}

Kata kunci: Ayam pedaging, temu putih, organ pencernaan, saluran pencernaan

\section{PENDAHULUAN}

Keberhasilan pada usaha peternakan ayam pedaging dinilai dari produksi daging yang dihasilkan. Pada proses pemeliharaan, pakan yang diberikan kepada ternak harus disesuaikan dengan kebutuhan nutrisi unggas. Kebutuhan nutrisi tersebut diberikan berdasarkan umur dan kondisi fisiologis ternak. Kondisi organ beserta saluran pencernaan 
merupakan salah satu komponen yang perlu diperhatikan untuk meningkatkan produktivitas secara maksimal. Saluran pencernaan mempunyai peranan penting dalam proses penyerapan nutrien pakan sehingga dapat dimanfaatkan oleh ternak. Saluran pencernaan mempunyai peran dalam proses mengubah nutrien yang ada di dalam pakan menjadi bentuk yang lebih sederhana dan dapat diabsorsi pada bagian intestinum. Apabila terjadi peningkatan ukuran pada bagian intestinum maka luas permukaan intestinum akan semakin luas sehingga mampu memaksimalkan proses penyerapan nutrien dan dapat membantu meningkatkan produktivitas ternak.

Kandungan nutrien pakan yang diberikan pada ternak dapat memodulasi perkembangan dan fungsi saluran pencernaan, termasuk kondisi mikrobiota yang ada pada saluran pencernaan (Broom \& Kogut 2018) Usaha untuk meningkatkan kesehatan organ dan saluran pencernaan salah satunya dapat dilakukan dengan menggunakan berbagai pakan tambahan untuk ayam pedaging. Temu putih (Curcuma zedoaria Berg.) merupakan salah satu tanaman yang digunakan sebagai obat herbal. Badan Pengawas Obat dan Makanan pada tahun 2007 menyebutkan bahwa temu putih mengandung zat warna kuning (kurkuminoid) dan minyak atsiri, zingiberen, sineol, polisakarida, dan golongan lain. Minyak atsiri merupakan komponen yang paling dominan di dalam temu putih yang mempunyai fungsi antikanker, antibakteri, anti jamur dan mempunyai kandungan antioksidan (Windono et al. 2002; Mau et al. 2003; Seo et al. 2005).

Kandungan zat aktif pada minyak atsiri tersebut diharapkan mampu menghambat pertumbuhan beberapa bakteri yang ada di saluran pencernaan sehingga proses penyerapan nutrien dapat berlangsung secara maksimal. Penelitian yang dilakukan oleh Windono et al. (2002) menyebutkan bahwa ekstrak etanol Curcuma zedoaria mampu menghambat pertumbuhan bakteri Escheria coli dan Bacillus substillis. Ekstrak etanol rimpang kering Curcuma zedoaria menunjukkan juga efek antifungi, dengan senyawa aktifetil-pmetoksisinamat (EPMS).

Tujuan penelitian yang dilaksanakan adalah untuk mengetahui pengaruh penambahan temu putih dalam pakan terhadap profil saluran dan organ pencernaan ayam pedaging.Penambahan temu putih dalam pakan diharapkan dapat memperbaiki kesehatan sistem pencernaan ternak sehingga dapat terjadi peningkatan ukuran pada saluran dan nutrien pakan dapat dikonsentrasikan pada proses pembentukan daging.

\section{MATERI DAN METODE}

\section{Ternak, pakan dan instrumen}

Penelitian ini menggunakan 100 ekor day old chick (DOC) Strain Cobb dengan rataan bobot 33,4 2,9 gram/ekor. Pemeliharaan dilakukan selama 40 hari pada kandang tertutup. Komposisi bahan pakan yang digunakan dalam penelitian ditampilkan pada Tabel 2. Pakan diformulasikan sesuai dengan kebutuhan nutrisi pada fase starter (23\% CP; $3100 \mathrm{kcal} / \mathrm{kg} \mathrm{ME;} \mathrm{0-21} \mathrm{hari)} \mathrm{dan} \mathrm{fase} \mathrm{finisher} \mathrm{(21 \%} \mathrm{CP;} 3200 \mathrm{kcal} / \mathrm{kg} \mathrm{ME;} \mathrm{22-35}$ hari) berdasarkan kebutuhan nutrien dan energi yang direkomendasikan oleh perusahaan breeder (Aviagen 2014). Pakan perlakuan diberikan pada fase finisher (ayam umur 15 hari sampai panen). Pemberian ransum sesuai kebutuhan dan air minum diberikan secara ad libitum. Vaksin ND Lasota dan ND IB masing-masing diberikan pada saat ternak berumur umur 4 hari dan 21 hari. 
Tabel 1. Kandungan nutrisi tepung temu putih

\begin{tabular}{lcccccc}
\hline \hline \multirow{2}{*}{ Bahan jamu } & \multicolumn{7}{c}{ Kandungan nutrisi (\%) } \\
\cline { 2 - 7 } & PK & LK & BK & SK & ABU & GE \\
\hline Temu putih & 5,67 & 1,31 & 92,67 & 3,20 & 11,67 & 3571,00 \\
\hline
\end{tabular}

Sumber: (Widodo 2019)

Tabel 2. Komposisi bahan pakan ransum penelitian

\begin{tabular}{lcccc}
\hline \hline Bahan baku (\%) & P1 & P2 & P3 & P4 \\
\hline Jagung kuning & 54,91 & 54,91 & 54,07 & 53,91 \\
Bekatul & 1,45 & 1,45 & 1,45 & 1,00 \\
Tepung ikan & 3,00 & 3,00 & 3,00 & 3,00 \\
Konsentrat & 12,8 & 12 & 12 & 12 \\
Minyak kelapa & 4,00 & 4,00 & 4,00 & 4,00 \\
Bungkil kedele & 21,36 & 21,2 & 22,2 & 21 \\
Kapur & 0,03 & 0,03 & 0,03 & 0,03 \\
Garam & 0,27 & 0,27 & 0,27 & 0,20 \\
Metionin & 0,16 & 0,16 & 0,16 & 0,16 \\
Lysin & 0,77 & 0,77 & 0,77 & 0,77 \\
Tepung tulang & 1,25 & 1,25 & 1,10 & 1,00 \\
Temu putih & 0,00 & 1,00 & 2,00 & 3,00 \\
\hline Total & 100,00 & 100,00 & 100,00 & 100,00 \\
\hline
\end{tabular}

\section{Rancangan penelitian}

Penelitian dianalisis menggunakan rancangan acak lengkap pola searah dengan menggunakan 4 perlakuan. Perbedaan antar perlakuan dilakukan uji lanjut menggunakan uji Beda Nyata Terkecil. Setiap kelompok perlakuan diberikan ulangan sebanyak 5 kali dan masing-masing ulangan terdiri dari 5 ekor ayam. Perlakuan yang diberikan pemberian tepung temu putih dengan taraf berbeda yaitu:

$$
\begin{aligned}
& \mathrm{P} 1=\text { pakan basal } \\
& \mathrm{P} 2=\mathrm{P} 1+1 \% \text { tepung temu putih } \\
& \mathrm{P} 3=\mathrm{P} 1+2 \% \text { tepung temu putih } \\
& \mathrm{P} 4=\mathrm{P} 1+3 \% \text { tepung temu putih }
\end{aligned}
$$

\section{Parameter yang diamati}

\section{Profil saluran pencernaan}

Data variabel yang diamati pada parameter profil saluran pencernaan adalah panjang absolut dan relatif duodenum, jejunum dan ileum. Panjang absolut saluran pencernaan didapat dengan mengukur panjang usus menggunakan pita ukur segera setelah ayam disembelih dan dilakukan pemisahan pada tiap bagian usus. Nilai panjang absolut usus halus ini disajikan dalam satuan $\mathrm{cm}$. 
Panjang relatif $(\%)=\frac{\text { Panjang usus }(\mathrm{cm})}{\text { Bobot badan ayam }(\mathrm{g})} \mathrm{X} \quad 100 \%$

\section{Organ pencernaan}

Data variabel yang diamati pada parameter profil organ adalah berat absolut dan relatif hati, pankreas, limpa, dan bursa fabricious. Berat absolut saluran pencernaan didapat dengan mengukur berat organ menggunakan timbangan digital segera setelah ayam disembelih. Nilai berat absolut organ pencernaan ini disajikan dalam satuan g.

$$
\text { Berat relatif }(\%)=\quad \frac{\text { Berat organ }(g)}{\text { Bobot badan ayam }(g)} \quad 100 \%
$$

\section{HASIL DAN PEMBAHASAN}

\section{Saluran pencernaan ayam pedaging}

Profil saluran pencernaan ayam pedaging yang diamati dalam penelitian ini meliputi panjang usus halus (duodenum, jejunum, ileum). Data penelitian didapatkan pada saat pengukuran hari ke-40 setelah dilakukan pemotongan ayam. Hasil pengamatan untuk saluran pencernaan ditampilkan pada tabel 3. Hasil pengamatan menunjukkan bahwa penggunaan tepung temu putih pada pakan ayam pedaging tidak mempengaruhi panjang duodenum (absolut dan relatif), jejunum (absolut) dan ileum (absolut dan relatif). Hal tersebut menunjukkan bahwa profil usus halus bagian duodenum, jejunum dan ileum tanpa atau menggunakan temu putih dianggap sama.

Tabel 3. Hasil pengamatan panjang absolut dan relatif usus halus ayam pedaging

\begin{tabular}{|c|c|c|c|c|c|c|}
\hline \multirow{2}{*}{ Variabel } & & \multicolumn{4}{|c|}{ Perlakuan } & \multirow{2}{*}{ P-value } \\
\hline & & P1 & $\mathrm{P} 2$ & P3 & P4 & \\
\hline \multirow{2}{*}{ Duodenum } & $\begin{array}{l}\text { Absolut } \\
(\mathrm{cm})\end{array}$ & $32,60 \pm 2,51$ & $30,20 \pm 3,19$ & $30,80 \pm 3,63$ & $32,20 \pm 3,11$ & 0,592 \\
\hline & $\begin{array}{l}\text { Relatif } \\
(\%)\end{array}$ & $1,25 \pm 0,10$ & $1,19 \pm 0,12$ & $1,24 \pm 0,14$ & $1,27 \pm 0,11$ & 0,712 \\
\hline \multirow{2}{*}{ Jejunum } & $\begin{array}{l}\text { Absolut } \\
(\mathrm{cm})\end{array}$ & $69,80 \pm 14,36$ & $84,80 \pm 4,55$ & $84,60 \pm 9,53$ & $88,60 \pm 12,90$ & 0,070 \\
\hline & $\begin{array}{l}\text { Relatif } \\
(\%)\end{array}$ & $2,69 \pm 0,61^{\mathrm{b}}$ & $3,35 \pm 0,28^{\mathrm{a}}$ & $3,42 \pm 0,38^{\mathrm{a}}$ & $3,49 \pm 0,31^{\mathrm{a}}$ & 0,027 \\
\hline \multirow{2}{*}{ Ileum } & $\begin{array}{l}\text { Absolut } \\
(\mathrm{cm})\end{array}$ & $83,00 \pm 30,6$ & $84,60 \pm 6,66$ & $80,20 \pm 10,26$ & $79,20 \pm 11,8$ & 0,958 \\
\hline & $\begin{array}{l}\text { Relatif } \\
(\%)\end{array}$ & $3,17 \pm 1,09$ & $3,33 \pm 0,16$ & $3,24 \pm 0,40$ & $3,12 \pm 0,354$ & 0,956 \\
\hline
\end{tabular}

Keterangan: $\mathrm{PI}=$ pakan basal; $\mathrm{P} 2=\mathrm{P} 1+1 \%$ tepung temu putih; $\mathrm{P} 3=\mathrm{P} 1+2 \%$ tepung temu putih; $\mathrm{P} 4=\mathrm{P} 1+3 \%$ tepung temu putih. Huruf superscript yang berbeda menunjukkan adanya perbedaan yang nyata antar perlakuan $(\mathrm{P}<0,05)$ pada tingkat kepercayaan $95 \%$

Penggunaan tepung temu putih pada pakan memberikan pengaruh pada panjang relatif jejunum ayam pedaging. Penggunaan tepung temu putih 3\% (P4) memberikan nilai 
jejunum terpanjang yaitu 88,60 cm dan 3,49\%, sedangkan ayam pedaging yang tidak diberi temu putih (P1) memberikan panjang jejunum lebih pendek dibandingkan perlakuan lainnya. Berdasarkan hasil pengamatan pada panjang relatif jejunum terjadi peningkatan $0,07 \%$ setiap penambahan level temu putih pada pakan ayam pedaging. Hasil uji lanjut menunjukkan bahwa penggunaan tepung temu putih sebesar 1-3\% menghasilkan panjang relatif jejunum yang lebih tinggi dibandingkan dengan perlakuan kontrol atau tanpa temu putih. Hal tersebut terjadi karena adanya kandungan zat aktif pada temu putih yang dapat merespon perkembangan jejunum.

Perlakuan pada pakan dapat mempengaruhi struktur dan fungsi usus halus. Pada pakan perlakuan terdapat tepung temu putih dimana kandungan paling dominan pada temu putih adalah minyak atsiri. Setyanto (2012) menyebutkan bahwa minyak atsiri mempunyai peranan dalam merangsang enzim saluran pencernaan, menghambat bakteri penyebab diare sehingga dapat memperbaiki kondisi saluran pencernaan. Widodo et al. (2002) menambahkan bahwa ekstrak etanol Curcuma zedoaria mampu menghambat pertumbuhan bakteri Escheria coli dan Bacillus substillis. Ekstrak etanol rimpang kering Curcuma zedoaria menunjukkan juga efek antifungi, dengan senyawa aktifetilpmetoksisinamat (EPMS).

Zat aktif yang terkandung di dalam temu putih tersebut diduga mampu meminimalisir adanya bakteri patogen dan dapat memberikan stimulus terhadap peningkatan ukuran usus jejenum. Beberapa literatur menyebutkan bahwa kandungan minyak atsiri yang terdapat pada rimpang temu putih berkisar anatara 1,0-2,50\% (Dalimartha 2005; Novalina 2003).

Panjangnya usus halus bagian jejunum dapat membantu dalam meningkatkan proses pencernaan nutrien pakan. Yao et al. (2006) menyebutkan bahwa kemampuan proses penyerapan nutrisi dan pencernaan dapat dipengaruhi oleh panjang dan lebar penampang usus halus.Penelitian lain yang dilakukan oleh Ibrahim (2008) menunjukkan bahwa panjang dan lebar usus halus memiliki korelasi atau pengaruh yang positif secara signifikan terhadap peningkatan berat hidup ayam pedaging.

\section{Profil organ ayam pedaging}

Profil organ ayam pedaging yang diamati dalam penelitian ini meliputi berat absolut dan relatif hati, pankreas, bursa fabricious, dan limpa. Hasil pengamatan organ ayam pedaging ditampilkan pada tabel 4. Hasil pengamatan menunjukkan bahwa penggunaan tepung temu putih pada pakan ayam pedaging tidak mempengaruhi $(\mathrm{P}>0,05)$ berat absolut dan relatif organ. Hal tersebut menunjukkan bahwa kerja organ ayam pedaging yang menggunakan atau tanpa temu putih sama dan tidak terpengaruh dengan adanya kandungan zat aktif yang ada pada temu putih.

Nilai berat absolut dan relatif organ ayam pedaging tidak berpengaruh dengan penambahan tepung temu putih menunjukkan bahwa kinerja organ pada ayam pedaging masih dalam keadaan normal. Peningkatan ukuran organ merupakan salah satu respon adaptasi pada tubuh ternak apabila terjadi peningkatan kinerja organ. Etriwati et al. (2017) menyebutkan bahwa apabila fungsi limpa bertambah maka terjadi perubahan pada konsistensi dan ukuran limpa yaitu limpa akan membengkak. Limpa merupakan organ pertahanan sekunder yang berfungsi untuk memproduksi sel-sel limfosit dan berperan penting dalam menahan agen yang berhasil mencapai sirkulasi darah guna menahan invansi organisme atau toksin sebelum menyebar lebih luas. Rata-rata nilai berat absolut dan relatif limpa dan hati pada penelitian ini adalah 8,09 gram; 0,32\% dan 178,15 gram; $7,01 \%$. 
Tabel 4. Hasil pengamatan berat absolut dan relatif organ ayam pedaging

\begin{tabular}{|c|c|c|c|c|c|c|}
\hline \multirow{2}{*}{ Variabel } & & \multicolumn{4}{|c|}{ Perlakuan } & \multirow{2}{*}{ P-value } \\
\hline & & $\mathrm{P} 1$ & $\mathrm{P} 2$ & P3 & $\mathrm{P} 4$ & \\
\hline \multirow{2}{*}{ Hati } & $\begin{array}{l}\text { Absolut } \\
\text { (g) }\end{array}$ & $175,74 \pm 15,06$ & $176,24 \pm 16,29$ & $170,60 \pm 18,04$ & $190,00 \pm 41,3$ & 0,656 \\
\hline & $\begin{array}{l}\text { Relatif } \\
(\%)\end{array}$ & $6,75 \pm 0,54$ & $6,94 \pm 0,64$ & $6,89 \pm 0,72$ & $7,45 \pm 1,18$ & 0,554 \\
\hline \multirow{2}{*}{ Pankreas } & $\begin{array}{l}\text { Absolut } \\
\text { (g) }\end{array}$ & $14,18 \pm 2,41$ & $14,48 \pm 2,79$ & $15,18 \pm 3,37$ & $14,62 \pm 4,40$ & 0,970 \\
\hline & $\begin{array}{l}\text { Relatif } \\
(\%)\end{array}$ & $0,54 \pm 0,07$ & $0,58 \pm 0,14$ & $0,61 \pm 0,14$ & $0,57 \pm 0,15$ & 0,856 \\
\hline \multirow{2}{*}{$\begin{array}{l}\text { Bursa } \\
\text { Fabricious }\end{array}$} & $\begin{array}{l}\text { Absolut } \\
\text { (g) }\end{array}$ & $17,38 \pm 6,52$ & $15,04 \pm 2,84$ & $14,38 \pm 3,26$ & $15,54 \pm 3,94$ & 0,733 \\
\hline & $\begin{array}{l}\text { Relatif } \\
(\%)\end{array}$ & $0,66 \pm 0,23$ & $0,59 \pm 0,11$ & $0,58 \pm 0,13$ & $0,61 \pm 0,15$ & 0,871 \\
\hline \multirow{2}{*}{ Limpa } & $\begin{array}{l}\text { Absolut } \\
\text { (g) }\end{array}$ & $7,44 \pm 1,71$ & $6,82 \pm 1,56$ & $9,50 \pm 2,62$ & $8,58 \pm 1,78$ & 0,180 \\
\hline & $\begin{array}{l}\text { Relatif } \\
(\%)\end{array}$ & $0,29 \pm 0,07$ & $0,27 \pm 0,07$ & $0,38 \pm 0,11$ & $0,34 \pm 0,04$ & 0,121 \\
\hline
\end{tabular}

Keterangan: $\mathrm{PI}=$ pakan basal; $\mathrm{P} 2=\mathrm{P} 1+1 \%$ tepung temu putih; $\mathrm{P} 3=\mathrm{P} 1+2 \%$ tepung temu putih; $\mathrm{P} 4=\mathrm{P} 1+3 \%$ tepung temu putih

Rata-rata nilai berat absolut dan relatif pankreas pada penelitian ini adalah 14,6 gram dan 0,45\%. Berat pankreas tersebut masih dalam kisaran normal. Berat relatif pankreas tersebut sejalan dengan penelitian yang dilakukan oleh Aqsa et al. (2016) yang menyebutkan bahwa berat pankreas rata-rata ayam pedaging yang diberi pakan dengan campuran tepung daun sirih sebesar $0,32 \%$. Berat pankreas ayam yang masih berada dalam kisaran normal mempunyai berat sekitar 0,25-0,40\% dari bobot hidup.Rata-rata nilai berat absolut dan relatif bursa fabricious pada penelitian ini adalah 15,58 gram dan $0,61 \%$.

\section{KESIMPULAN}

Penambahan tepung temu putih pada pakan ayam pedaging hingga taraf 3\% tidak memberikan respon terhadap profil saluran dan organ pencernaan ayam pedaging.

\section{DAFTAR PUSTAKA}

Aviagen. 2014. Broiler management handbook aviagen. Huntsville (USA): Aviagen. hlm. 30.

Aqsa AD, Kiramang K, Hidayat MN. 2016. Profil organ dalam ayam pedaging (broiler) yang diberi tepung daun sirih (Piper betle Linn) sebagai imbuhan pakan. J Ilmu Industri Peternakan. 3:148-159.

[BPOM] Badan Pengawas Obat dan Makanan. 2005. Gerakan nasional minum temulawak. InfoPOM. 6:1-4. 
Dalimartha S. 2005. Atlas tanaman obat Indonesia. Jilid 3, Cetakan ke-4. Jakarta (Indonesia): Puspa Swara. hlm. 170-171.

Etriwati, Ratih D, Handharyani E, Setiyaningsih S. 2017. Studi histopatologi limpa dan bursa fabricious ayam berpenyakit tetelo (Newcastle Disease) pada kasus lapang. J Veteriner. 18:510-515.

Glick B. 2000. Immunophysiology. In: Sturkie PD, editor. Sturkie’s Avian Physiology. 5th ed. San Diego (USA). Academic Press. p. 657-667.

Grist A. 2006. Poultry inspection-anatomy, physiology and disease conditions. 2nd ed. Nottingham (United Kingdom): Nottingham University Press.

Hazelwood RL. 2000. Pancreas. Dalam: Sturkie’s Avian Physiology. 5th ed. San Diego (USA). Academic Press. hlm 539-555.

Ibrahim S. 2008. Hubungan ukuran-ukuran usus halus dengan berat badan broiler. Agripet. 8:42-46.

Jain NC. 1993. Essentials of veterinary hematology. Philadelphia (USA): Lea and Febiger. hlm. 365-372.

Setyanto A, Atmomarsono U, Muryani R. 2012. Pengaruh penggunaan tepung jahe emprit (Zingiber officinale var Amarum) dalam ransum terhadap laju pakan dan kecernaan pakan ayam kampung umur 12 minggu. Anim Agric J. 1:712.

Yao Y, Xiaoyan T, Haibo X, Jincheng K, Ming X, Xiaobing W. 2006. Effect of choice feeding on performance gastrointestinal development and feed utilization of broilers. Asian-Aust J Anim Sci. 19:91-96.

Windono T. 2002. Kunir putih, temu putih dan kemuning. Prosiding Seminar Nasional Tumbuhan Obat Indonesia XXI. Surabaya (Indonesia): Universitas Surabaya. 